\title{
DA UNIVERSALIZAÇÃO DO ACESSO À ESCOOLA NO BRASIL
}

\author{
Alceu Ravanello Ferraro \\ Nádie Christina Ferreira Machado*
}

\begin{abstract}
RESUMO: $\mathrm{O}$ artigo analisa como se distribuem pelo território nacional os 8,1 milhôes de crianças e adolescentes brasileiros de 4 a 17 anos, que em 1996 não freqüentavam escola. Questiona-se em particular a tese segundo a qual a universalização do acesso à escola estaria assegurada no Brasil desde os anos 80 , a qual reduz o não-acesso a algo como $5 \%$. As taxas de não-freqüência à escola em 1996, para as pessoas de 4 até 17 anos, são sempre superiores a $5 \%$, ultrapassando o nível de $20 \%$ nos grupos extremos, isto é, dos 4 aos 6 anos e dos 15 aos 17 anos. O nãoacesso à escola, portanto, ainda é um problema real no Brasil. Elevadas taxas de pessoas que nunca ingressaram na escola não se limitam ao Nordeste, estendendo-se também a estados como Amazonas e Pará, na Região Norte. As taxas de exclusão da escola são sempre mais elevadas para o sexo masculino do que para o feminino. Sob o aspecto conceptual, a noção de não-acesso deve compreender não apenas os que nunca freqüentaram escola, mas também aqueles que, tendo freqüentado e ainda em idade escolar, se encontram fora da escola.

Palavras-chave: Educação. Escolarização. Acesso à escola. Exclusão da escola. Brasil.
\end{abstract}

Professor da Escola Superior de Teologia, em São Leopoldo/RS. Professor Titular aposentado da Universidade Federal do Rio Grande do Sul. Ex-Professor Titular do PPG em Desenvolvimento Social e da Escola de Serviço Social da Universidade Católica de Pelotas, onde foi desenvolvida a pesquisa. Pesquisador do CNPq e coordenador do projeto. Em 1993, o sobrenome Ferrari foi retificado para Ferrraro. E-mail: aferraro@adufrgs.ufrgs.br

** Psicóloga pela Universidade Católica de Pelotas. Mestranda em Educação pela UFRGS. Participação na pesquisa como bolsista de Apoio Técnico Nível Superior do CNPq, especialmente na elaboração e teste do modelo de análise, na organização das tabelas e gráficos e na análise dos resultados e elaboração do texto final.E-mail: mnadiechristina@aol.com 
About the universalization of SCHOOL aCCess IN BRAZIL

ABSTRACT. This paper analyses how the 8.1 million Brazilian children and adolescents between 4-17 years who did not attend class in 1996 distribute throughout the national territory. It particularly questions the thesis that asserts that the school access universalization is guaranteed in Brazil since the 80 s and that nonattendance stands around 5\%. In 1996, the rates of non-attendance to school for youths between 4-17 years were always above 5\% and even exceeded $20 \%$ in extreme groups, that is, youngsters between 4-6 or 15-17 years. Therefore, non-attendance to school continues being a real problem in Brazil. High rates of people who have never gone to school are not restricted to Northeastern Brazil, but also extend to such states as Amazonas and Pará, in Northern Brazil. The rates of school exclusion are always higher for males than for females. From a conceptual point of view, the notion of non-access must include not only the people who have never attended school, but also those who, even though in school age, are out of school.

Key words: Education. Schooling. School access. School exclusion. Brazil.

\section{Introdução}

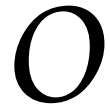

presente artigo versa sobre a questão da universalização do acesso à escola no Brasil, tendo como base empírica a Contagem da População 1996 (IBGE, 1997). ${ }^{1}$ Ele apresenta parte dos resultados da pesquisa Exclusão da escola no Brasil segundo a Contagem da População 1996, dando continuidade e buscando aprofundar um aspecto de pesquisa anterior, ${ }^{2}$ precisamente o relacionado com a questão da exclusão da escola ou, dito de forma positiva, com a questão da universalização do acesso à escola. Esta é uma das dimensões do fenômeno da exclusão escolar, que se desdobra nas categorias exclusão da escola e exclusão na escola (Ferrari, 1985 e 1987), referindo-se a primeira à questão do acesso e permanência na escola, e a segunda, à questão do sucesso ou não no processo de escolarização.

A atualidade e relevância do tema residem no fato de que, na Contagem 1996, o IBGE desagregou a categoria não freqüentam em duas subcategorias: nunca freqüentaram e já freqüentaram, o que permite uma análise mais acurada do fenômeno descrito estatisticamente como não-freqüência à escola, interpretado como não-acesso, e melhor definido conceitualmente como exclusão da escola. 


\section{Justificativa e perspectiva de análise}

Na pesquisa anterior (Ferraro, 1999a e 1999b) a atenção esteve voltada para a dupla dimensão do processo de exclusão escolar: a exclusão da escola e a exclusão na escola, construção teórico-metodológica que tem fundamentado uma série de estudos sobre alfabetização/analfabetismo e escolarização desde meados dos anos 80 . Por excluídos da escola entendem-se todos aqueles que, devendo freqüentar a escola, não o fazem, independentemente de já a haverem ou não freqüentado no passado. A categoria dos excluídos na escola compreende todos aqueles que, mesmo estando na escola, por ingresso tardio ou por força de sucessivas reprovações e repetências acusam forte defasagem (de dois ou mais anos) nos estudos.

O presente artigo pretende aprofundar a compreensão da primeira dimensão da exclusão escolar - a exclusão da escola. A perspectiva da análise aqui desenvolvida contrapóe-se à tese que dá como já realizada a universalização do acesso à escola no Brasil, tese esta sustentada desde meados da década de 1980 por um grupo de pesquisadores, cujos trabalhos vêm inspirando o discurso oficial e subsidiando a formulação da política nacional de educação básica, em particular a de educação fundamental.

A abordagem desenvolvida no presente artigo tem uma história que não pode deixar de ser retraçada, o que será feito passo por passo, a seguir.

\section{Acesso à escola em 1979/1980: duas avaliações discordantes}

Em 1985 foram publicados dois trabalhos independentes, que apresentaram resultados contrastantes. Trata-se de dois artigos: um, de Fletcher (1985); o outro, de Ferrari (1985). Fletcher propunha-se mostrar três coisas em seu artigo: primeiro, que o problema da repetência, tal como era correntemente definido, era incorretamente especificado; segundo, que a incidência da evasão era superdimensionada e, terceiro, que a principal causa da saída extemporânea da escola no Brasil era, de fato, a repetência (Fletcher, 1985, p. 11). Em suma, a tese do referido autor era de que o grande problema da escola brasileira não estava na evasão, mas sim na reprovação e repetência. Até aqui, nada a objetar, nem então, nem hoje, até porque essa constatação não era algo totalmente novo. Dez anos antes, dados levantados diretamente dos cadernos de chamada de 172 turmas de primeira série primária das escolas municipais de 
cinco cidades do Vale do Rio dos Sinos, na Região Metropolitana de Porto Alegre, haviam indicado duas coisas: 1) que a evasão representava um percentual de apenas $4,0 \%$ contra $33,5 \%$ de reprovação na $1^{\text {a }}$ série; 2) que, além da evasão e reprovação, as escolas tinham em seus registros (nos cadernos de chamada) uma categoria estranha às estatísticas oficiais, denominada não-comparecimento às provas, categoria esta que deveria somar-se à reprovação, mas que provavelmente acabava engrossando as estatísticas oficiais de evasão escolar. Nesse caso, a taxa de evasão representava apenas $1 / 10(4,0 \%)$ da taxa de reprovação + não-comparecimento às provas $(39,6 \%)$ (Ferrari, 1975 , p. 60). Mesmo assim, considera-se um equívoco a pretensão de encontrar na gravidade do problema da reprovação e repetência argumento para minimizar e desqualificar o problema da evasão. ${ }^{3}$

O ponto principal da divergência em relação a Fletcher é outro. No desenvolvimento de sua argumentação no referido artigo, o autor inaugurou uma tendência clara de minimização e desqualificação do problema do acesso à escola, ou seja, uma tendência de dar por já realizada, ou quase, a universalização do acesso ao ensino fundamental. Com base nas estatísticas de matrícula de 1979 e da população residente segundo o Censo Demográfico de 1980, o autor estimava que, no ano de 1979, no Brasil, 89,6\% das crianças de nove anos de idade estavam, ao menos oficialmente, matriculadas no primeiro grau, sugerindo que quase todos nesta geração mais nova tinham "alguma exposição a esta instituição escolar" (Fletcher, 1985, p. 21). Partindo da suposição de que metade dos 10,4\% de não matriculados entre as crianças de nove anos de idade já se teria matriculado previamente e depois abandonado a escola, o autor concluía que cerca de $95 \%$ das crianças de nove anos de idade estariam na escola ou já teriam passado por ela.

Ora, praticamente no mesmo momento em que era publicado o artigo de Fletcher, aparecia outro estudo (Ferrari, fevereiro de 1985), apoiado em dados do Censo Demográfico de 1980, com resultados bem diferentes. De acordo com este segundo estudo, para a mesma população de nove anos de idade a taxa de não-freqüência à escola representava, em $1980,28,4 \%$, sendo a mesma taxa da ordem de $14,3 \%$ no meio urbano e de 52,6\% no meio rural. Ainda segundo a mesma fonte, a não-freqüência à escola na faixa de 7 a 14 anos somava, em 1980, quase 7,6 milhões de crianças e adolescentes, equivalendo a justos $33 \%$ do total de crianças e adolescentes nessa faixa de idade, dos quais quase 2,8 milhões no meio urbano e cerca de cinco milhões no meio rural (Ferrari, 1985, p. 46, tabela 6). Vale ressaltar que a taxa de não-freqüência à escola entre as 
crianças de nove anos no Brasil, acusada pelo Censo de 1980 (28,4\%), representa nada menos de que 2,7 vezes a taxa apurada por Fletcher com base nos dados de matrícula obtidos dos registros escolares pelo SEEC/ MEC (10,4\%). É muita diferença para não levá-la em conta.

\section{O discurso da universalização}

Um ano mais tarde, Fletcher \& Castro (1986) apontaram as baterias contra o que denominavam os onze mitos sobre o ensino de $1^{\circ}$ grau. Para o que aqui interessa, destacam-se o mito de que "Uma proporção significativa da população em idade escolar não tem acesso ao ensino de $1^{\circ}$ grau" e o mito de que "O principal problema do ensino de $1^{\circ}$ grau é a evasão". Realizada essa dupla desmitificação, isto é, reduzidos a dimensões pouco significativas o não-acesso e a evasão, os autores concluíam que "a reprovação com sua conseqüente repetência adquire importante relevo". Segundo eles, considerando que "o ensino de $1^{\circ}$ grau alcançou um número de matrículas suficiente para oferecer oito séries de ensino a todas as pessoas numa geração", a eliminação da repetência seria a melhor maneira de se conseguir simultaneamente a ampliação do acesso ao sistema e a redução da evasão. Os autores chegaram a sugerir que se devia considerar seriamente a alternativa da promoção automática (op. cit., p. 41).

Alguns anos mais tarde, Castro voltou ao assunto com a pergunta “Onde está o desastre?”. Referindo-se aos estudos de Fletcher \& Ribeiro, conclui: "Se esta análise está correta, muda toda a política educacional para o ensino básico". Segundo o autor, se não houvesse repetência, exceção feita de alguns problemas geograficamente localizados, como o Nordeste rural, e de algumas escolas congestionadas em cerdas cidade, "não faltam nem prédios e nem professores para oferecer este ensino" (Castro, 1989, p. 32). Já teríamos, assim, segundo os autores, vencido a etapa da quantidade e entrado na "etapa da qualidade do ensino" (op. cit., p. 32).

O ponto de discordância em relação aos autores citados não está na ênfase que colocam no problema da reprovação/repetência. Está, sim, no fato de minimizarem os problemas habitualmente denominados evasão e não-acesso. O problema do acesso não se resolve simplesmente com professores e vagas nas escolas. É necessário, também, que os candidatos à escola tenham condições de ingressar e permanecer na escola, com sucesso, pelo tempo a que têm direito. É verdade, mas não é toda a verdade, que os alunos vão ficando mais velhos e mais frustrados até atingirem "uma idade em que a ida para o mercado de trabalho já é 
quase uma imposição econômica dentro do orçamento familiar apertado", como diz Castro (1989, p. 32). É necessário também lembrar as situações nada incomuns de trabalho infantil, em que crianças de 10 a 14 anos, e até de menos de 10 anos, antes mesmo do ingresso na escola ou logo nos primeiros anos de escolarização, são desafiadas à difícil conciliação entre trabalho e escola ou, não raro, postas ante o dilema de ter que optar entre trabalho e escola, como recentemente demonstrado em relação ao estado do Rio Grande do Sul (Ferraro, 1997).

Em 1990, Sérgio da Costa Ribeiro retomou a questão em artigo intitulado "A pedagogia da repetência". Aparecem aí a mesma ênfase na reprovação e repetência, por oposição à ênfase historicamente dada à evasão, e a mesma minimização explícita da questão do acesso à escola. Segundo o autor, a universalização do acesso já estava praticamente assegurada; entendia que se estava "caminhando rapidamente para a universalização do acesso à escola no Brasil", uma vez que, pelos dados do Profluxo, cerca de $93 \%$ de uma geração tinham acesso à escola no Brasil. E concluía: "Este dado, por si só, evidencia que o acesso à escola de $1^{\circ}$ grau está praticamente universalizado no país, ao contrário do que é propalado de que milhões de crianças fora da escola é uma conseqüência da falta de matrículas para o acesso" (Ribeiro, 1990, p. 14).

No ano seguinte, Ruben Klein e Sérgio da Costa Ribeiro publicaram longo e minucioso artigo, intitulado "O censo educacional e o modelo de fluxo: O problema da repetência" (Klein e Ribeiro, 1991), onde novamente teceram duras críticas ao sistema de dados estatísticos sobre educação no Brasil, principalmente no que se relaciona com os dados dos censos escolares. Os autores apresentaram uma série de sugestôes interessantes para melhorar os instrumentos de coleta dos censos educacionais, das PNADs e dos censos demográficos. No entanto, em relação aos censos escolares, é importante observar que há um problema anterior, que pode comprometer os dados oriundos dos registros escolares, mesmo que os instrumentos de coleta sejam adequados. Trata-se dos próprios registros escolares, isto é, da maneira como são definidos e anotados nos registros escolares os diferentes eventos da vida escolar de cada aluno durante o ano letivo. Esta questão é abordada em outro texto, onde são analisados os resultados de estudo exploratório conduzido justamente com o objetivo de chamar a atenção para os problemas relacionados com os registros escolares, a verdadeira fonte das estatísticas do movimento anual do sistema de educação. Tal estudo contemplou as primeiras séries das escolas públicas do bairro Fragata, na cidade de Pelotas, tendo como referência o ano de $1998 .{ }^{4}$ 
Feita essa digressão sobre os registros escolares, volta-se à questão de fundo que se vinha discutindo. Também no ano de 1991, precisamente no momento em que se realizava o censo demográfico daquele ano, na VI Conferência Brasileira de Educação no Painel Diagnóstico do atendimento escolar básico: posiçôes, Sérgio da Costa Ribeiro radicalizava a sua posição relativamente ao problema do acesso à escola. "Hoje" - dizia ele então - "o acesso à escola está praticamente universalizado no país: 95\% das crianças entram na escola". E acrescentava: "Dos 5\% restantes, 2 ou $3 \%$ são excepcionais que não têm condições de freqüentar escolas, os 3 ou $2 \%$ restantes vivem em sua grande maioria (mais de $70 \%$ ) no Nordeste rural pobre, onde a renda familiar per capita é inferior a um salário mínimo" (Ribeiro, in: Soares, 1992, p. 26-27). E enfatizando mais uma vez que o grande problema não era a evasão, mas a reprovação, o autor voltava à tese da já realizada universalização do acesso nos seguintes termos:

O que este cenário está indicando é que apesar do progresso que representa a universalização do acesso à educação elementar em nosso país os mais importantes problemas da educação não foram sequer percebidos corretamente pela sociedade ou pelos governos. Hoje, matriculados no $1^{\circ} \mathrm{grau}$, está um número de indivíduos ligeiramente superior ao da população de 7 a 14 anos. Mesmo assim continua-se a construir escolas como se houvesse ainda crianças fora da escola por falta de vagas. Ignora-se completamente o problema que se passa dentro da escola, sua pedagogia, seu descompromisso com o aprendizado e com a promoção dos alunos. (Ribeiro, op. cit., 1992, p. 28)

A ênfase no compromisso com o que se passa dentro da escola, com o aprendizado e a promoção, pretendida com razão por Ribeiro, não deve levar à desqualificação sumária do problema do acesso. Em contraposição a essa linha de argumentação, no já referido painel da VI Conferência Brasileira da Educação, no trabalho "Atendimento escolar básico: problemas de diagnóstico" (Ferrari, in: Soares et al., 1992), destacou-se a contribuição dos três autores referidos (Fletcher, Castro e Ribeiro) em dois aspectos: "[...] primeiro, pela crítica a que submeteram as estatísticas educacionais, particularmente as relativas à evasão escolar, e segundo, pela ênfase dada ao problema da reprovação e repetência" (op. cit., p. 16). Justificou-se essa concordância, invocando dois argumentos. Primeiro, porque já no início dos anos 70, precisamente pelas "séries limitações nas estatísticas oriundas de registros escolares", optarase por tentar reconstruí-las a partir dos próprios registros escolares (Ferrari, 1975). Segundo, porque, conforme observado acima, os dados assim reconstruídos haviam confirmado, para a população das primeiras séries 
estudadas, um índice de reprovação 10 vezes maior do que o de evasão (Ferrari, in: Soares et al., 1992, p. 17).

Mas, destacadas as concordâncias, passou-se a focalizar o ponto de divergência em relação aos referidos autores. Discordava-se deles por insistirem em dar por já praticamente realizada a universalização do acesso à escola fundamental no país, apequenando assim o problema do acesso à escola (Ferrari, op. cit., p. 17). Fundamentava-se a discordância em dois argumentos. Invocava-se, primeiramente, a experiência de Cuba. Esta, dentro de um processo revolucionário, levara mais de dez anos para elevar a taxa de aprovação na escola primária de cerca de 50 a 60\% em 1962/63 para aproximadamente $85 \%$ em $1973 / 74$, ao mesmo tempo em que se verificava uma explosão do sistema escolar, tanto no número de escolar e de alunos, quanto principalmente no número de professores. Nesses termos, a julgar pela experiência cubana, que representa uma situação privilegiada, o objetivo da eliminação da reprovação deveria ser redefinido para redução progressiva da reprovação, e assim mesmo só realizável no longo prazo. Isto equivalia a dizer que a hipótese dos autores de que há escola para todos só se iria tornando realidade, na medida em que se fosse efetivamente operando e consolidando a redução das taxas de reprovação.

O segundo argumento era buscado no Censo de 1980, segundo o qual 33\% das crianças e adolescentes de 7 a 14 anos e 28,4\% das crianças de 9 anos de idade estavam fora da escola, o que contrastava de forma gritante com as estimativas do Profluxo. Anos mais tarde, quando publicados, os dados do Censo Demográfico de 1991 revelaram duas coisas: de um lado, que houve uma sensível melhora na década de 1980 em termos de incorporação ao sistema escolar; mas, de outro, que significativa parcela da população em idade escolar - quase 5,7 milhões dentre o total de pessoas de 7 a 14 anos - permanecia fora da escola, com os índices mínimos da ordem de $16,6 \%, 15,1 \%$ e $15,3 \%$, respectivamente aos 9,10 e 11 anos de idade, índices estes três vezes mais elevados do que os estimados por Ribeiro para o ano de 1991 (cerca de 5\% aos 9 anos). ${ }^{5}$ Como se verá adiante, o qüinqüênio 1991/96 conheceu avanço ainda maior nos níveis de escolarização da população do que no período 1980/91. O que está em questão não é a tendência histórica rumo à universalização do acesso à escola, mas o nível de realização desse objetivo.

\section{Metodologia}

$\mathrm{O}$ objetivo principal da pesquisa refere-se justamente à questão da exclusão da escola. Ora, conforme já se disse acima, o contato com os 
dados da Contagem da População 1996 no projeto anterior (Alfabetização e escolarização de crianças e adolescentes de 5 a 17 anos no Brasil) revelou uma grata surpresa: a desagregação da categoria não freqüentam em duas subcategorias: já freqüentaram e nunca freqüentaram. Assim, essa pesquisa do IBGE permite avaliar, para cada idade, o contingente e o percentual dos que nunca freqüentaram e daqueles que já freqüentaram dentre o total compreendido pela categoria não freqüentam escola. Viu-se acima a insinuação de que, dos 5\% que, no início dos anos 90, não tinham acesso à escola, 2 ou $3 \%$ seriam excepcionais, sem condições de freqüentar escola, e os 3 ou $2 \%$ restantes viveriam em sua maioria no Nordeste rural pobre (Ribeiro, 1992).

Obviamente, não há maneira de se avaliar, com base nas estatísticas da Contagem 1996, o peso da categoria excepcionais no conjunto da não-freqüência. Em artigo anterior (Ferraro, 1999b), aferiu-se a evolução 1980/91/96 da distribuição da população em termos de freqüência e não-freqüência para cada idade. Este aspecto será retomado a seguir, mas o objetivo principal aqui será, com base na Contagem 1996, tentar avançar na compreensão do fenômeno do não-acesso, introduzindo uma distinção importante, qual seja, a de estabelecer, para as diferentes idades dos 4 ou 5 aos 17 anos, a participação relativa das subcategorias já freqüentaram e nunca freqüentaram na composição da categoria não freqüentam.

O modelo de organização, processamento e análise dos dados da Contagem 1996 foi testado inicialmente para o Brasil e depois aplicado sucessivamente a cada uma das Unidades da Federação. O núcleo do modelo de análise é dado pelas tabelas 2 e 3 e pelo gráfico 1 .

Esclarecidos esses aspectos metodológicos, pode-se passar à análise dos resultados, iniciando pela evolução da não-freqüência (da exclusão da escola) no período 1980-1996.

5. A ampliação do acesso à escola à luz da queda das taxas de exclusão no período 1980/1996

Retomam-se, neste item, alguns resultados de pesquisa anterior, já de domínio público (Ferraro, 1999a e 1999b).

Período 1980/91. Conforme observado acima, o Censo de 1980 revelou que, naquele ano, o contingente de crianças e adolescente de 7 a 14 anos que não freqüentavam escola (excluídos da escola) beirava os 7,6 milhões, representando $33 \%$ do total nessa faixa de idade, o 
que contrastava com as estimativas de Fletcher (1985) para o ano de 1979. Se aos fora da escola no grupo de 7 a 14 anos (7,6 milhões) se somarem também os dos grupos de 5 a 6 anos (4,7 milhões) e 15 a 17 anos (4,3 milhôes), o contingente total de crianças e adolescentes brasileiros de 5 até 17 anos que não freqüentavam escola no momento do Censo de 1980 atingiria o assombroso número de 16,6 milhões (Tabela 1).

\section{Tabela 1}

Número de crianças e adolescentes que não freqüentavam escola, segundo a idade, Brasil - 1980, 1991, 1996.

\begin{tabular}{|c|c|c|c|c|c|c|}
\hline & \multicolumn{2}{|l|}{1980} & \multicolumn{2}{|l|}{1991} & \multicolumn{2}{|l|}{1996} \\
\hline Idade & Número & $\%$ & Número & $\%$ & Número & $\%$ \\
\hline 4 anos & $\ldots$ & $\ldots$ & $\ldots$ & $\ldots$ & 1865747 & 59,4 \\
\hline 5 anos & 2528254 & 81,9 & 2497715 & 72,4 & 1332353 & 42,4 \\
\hline 6 anos & 2133566 & 71,9 & 1805756 & 53,0 & 727224 & 22,3 \\
\hline 7 anos & 1417380 & 47,4 & 988818 & 29,1 & 363421 & 10,8 \\
\hline 8 anos & 1001593 & 34,5 & 708259 & 19,9 & 256852 & 7,8 \\
\hline 9 anos & 801294 & 28,4 & 599226 & 16,6 & 223416 & 6,7 \\
\hline 10 anos & 813571 & 28,3 & 543152 & 15,1 & 231730 & 6,6 \\
\hline 11 anos & 726720 & 25,9 & 545824 & 15,3 & 239728 & 7,1 \\
\hline 12 anos & 827568 & 28,2 & 623698 & 18,4 & 295093 & 8,7 \\
\hline 13 anos & 883039 & 32,0 & 730857 & 22,2 & 420490 & 11,8 \\
\hline 14 anos & 1082576 & 38,2 & 923762 & 28,8 & 619473 & 16,9 \\
\hline 15 anos & 1296428 & 44,8 & 1157275 & 36,7 & 850845 & 24,1 \\
\hline 16 anos & 1456958 & 51,5 & 1393347 & 45,0 & 1162001 & 33,0 \\
\hline 17 anos & 1590744 & 57,9 & 1577099 & 52,9 & 1420101 & 42,8 \\
\hline 5 & 4661820 & & 4303471 & & 2059577 & \\
\hline 7 a 9 anos & 3220267 & & 2296303 & & 1347497 & \\
\hline 10 a 14 anos & 4333474 & & 3367293 & & 1806514 & \\
\hline 7 a 14 anos & 7553741 & & 5663596 & & 3154011 & \\
\hline 15 a 17 anos & 4344130 & & 4127721 & & 3423947 & \\
\hline 7 a 17 anos & 11897871 & & 9791317 & & 6586958 & \\
\hline 5 a 17 anos & 16559691 & & 14094788 & & 8646535 & \\
\hline
\end{tabular}

Fontes: IBGE, Censo Demográfico - 1980; Censo Demográfico - 1991;

Contagem da População - 1996.

Elaboração: Alceu R. Ferraro 
O Censo de 1991 fez dupla revelação relativamente ao que aqui interessa (Tabela 1). A primeira vai na direção do movimento histórico secular de expansão do sistema escolar e de regressão do analfabetismo. Nessa perspectiva, verificou-se, entre 1980 e 1991, uma diminuição sensível no número absoluto dos não-freqüentes no grupo de 7 a 14 anos, o qual baixou de quase 7,6 milhōes em 1980 para cerca de 5,7 milhões em 1991. Mas, há outra revelação: no mesmo período 1980/ 91, a redução absoluta no número dos excluídos da escola praticamente se limitou ao grupo de 7 a 14 anos. Com efeito, nos grupos de 5 a 6 anos e de 15 a 17 anos, o número dos não-freqüentes se manteve praticamente no mesmo nível, apresentando uma redução muito pequena: de quase 4,7 milhões para 4,3 milhões, no grupo de 5 a 6 anos; e de cerca de 4,3 milhôes para cerca de 4,1 milhões, no grupo de 15 a 17 anos.

Em termos relativos, levando-se agora em conta a expansão da população no período, os ganhos foram maiores (Tabela 1). Mas, também em termos percentuais, os ganhos foram mais acentuados no grupo de 7 a 14 anos, do que nos grupos de 5 a 6 anos e 15 a 17 anos. Os menores ganhos - as menores reduções na taxa de não-freqüência - verificaram-se nos extremos: de um lado, aos 5 anos, e de outro, aos 17 anos. No grupo de 7 a 14 anos, a taxa mínima de não-freqüência, que era de $25,9 \%$ aos 11 anos em 1980, baixou para 15,1\% aos 10 anos em 1991. Já as taxas máximas de não-freqüência no grupo de 7 a 14 anos, verificadas sempre nos extremos dessa faixa etária, baixaram, no mesmo período, de $47,4 \%$ para $29,1 \%$ anos 7 anos e de $38,2 \%$ para $28,8 \%$ aos 14 anos.

De um lado, pois, é mister reconhecer os ganhos realizados na década de 1980 em termos de escolarização, particularmente na faixa de 7 a 14 anos. De outro, em direção oposta, os mesmos números, absolutos e percentuais, que atestam o progresso realizado, também denunciam tudo o que, em 1991, ainda estava por se conquistar. Em particular, os índices mínimos de não-freqüência apurados em 1991, da ordem de $16,6 \%, 15,1 \%$ e $15,3 \%$, respectivamente aos 9,10 e 11 anos de idade, eram três vezes mais elevados do que os $5 \%$ estimados por Ribeiro (1992) para as crianças de 9 anos de idade relativamente ao mesmo ano de 1991.

Período 1991/96. Comparativamente aos 11 anos do período 1980/91, o qüinquiênio 1991/96 conheceu uma redução muito mais significativa dos níveis de exclusão da escola em todas as idades aqui estudadas - dos 5 anos 17 anos (Tabela 1). Na faixa de 9 a 11 anos, as taxas de não-frequiência baixaram para níveis entre 6,6 e 7,1\%, agora sim se aproximando da estimativa de $5 \%$ feita por Ribeiro para o ano de 


\section{Tabela 2}

Pessoas de 4 a 17 anos de idade, segundo o sexo e freqüência à escola, por idade. Brasil, 1996.

\begin{tabular}{|c|c|c|c|c|c|c|c|c|c|c|c|c|c|c|c|c|}
\hline \multirow{3}{*}{\multicolumn{2}{|c|}{\begin{tabular}{|c|} 
SEXO E \\
FREQUÊNCIA À ESCOLA \\
\end{tabular}}} & \multirow[b]{2}{*}{ TOTAL } & \multirow[b]{2}{*}{4} & \multirow[b]{2}{*}{5} & \multirow[b]{2}{*}{6} & \multirow[b]{2}{*}{7} & \multicolumn{4}{|c|}{ PESSOAS DE 4 a 17 ANOS } & \multirow[b]{2}{*}{12} & \multirow[b]{2}{*}{13} & \multirow[b]{2}{*}{14} & \multirow[b]{2}{*}{15} & \multirow[b]{2}{*}{16} & \multirow[b]{2}{*}{17} \\
\hline & & & & & & & 8 & \begin{tabular}{|l|}
9 \\
\end{tabular} & 10 & 11 & & & & & & \\
\hline & & & anos & anos & anos & anos & anos & anos & anos & anos & anos & anos & anos & anos & anos & anos \\
\hline \multirow{9}{*}{ 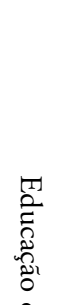 } & TOTAL & 144593327 & 3138426 & 3142666 & 3258564 & 3349559 & 3307939 & 3338215 & 3502135 & 3392397 & 3404956 & 3559828 & 3657661 & 3531140 & 3520567 & 3317571 \\
\hline & FREQUENTAM & 44277285 & 1022486 & 1754644 & 2510718 & 2980016 & 3046508 & 3110538 & 3263402 & 3145966 & 3102896 & 3132455 & 3033728 & 2676268 & 2354451 & 1893825 \\
\hline & NÃO FREQUENTAM & 99730457 & 1865747 & 1332353 & 727224 & 363421 & 256852 & 223416 & 231730 & 239728 & 295093 & 420490 & 619473 & 850845 & 1162001 & 1420101 \\
\hline & JA FREQUENTARAM & 80552784 & 144 & 24855 & 43446 & 64457 & 74538 & 86150 & 106909 & 135402 & 196959 & 321453 & 514133 & 737645 & 1034843 & 1291735 \\
\hline & NUNCA FREQUENTARAM & 18979366 & 1853933 & 1298562 & 678225 & 295938 & 179909 & 134869 & 122196 & 101787 & 95649 & 96068 & 103270 & 110747 & 123519 & 123176 \\
\hline & SEM DECLARAÇÃO & 198307 & 11670 & 8936 & 5553 & 3026 & 2405 & 2397 & 2625 & 2539 & 2485 & 2969 & 2070 & 2453 & 3639 & 5190 \\
\hline & SEM DECLARAÇÃO & 585585 & 250193 & 55669 & 20622 & 6122 & 4579 & 4261 & 7003 & 6703 & 6967 & 6883 & 4460 & 4027 & 4115 & 3645 \\
\hline & HOMENS & 71106905 & 1595715 & 1597898 & 1652992 & 1703577 & 1680602 & 1688817 & 1778986 & 1719997 & 1719423 & 1790649 & 1833249 & 1767097 & 1761896 & 1666073 \\
\hline & FREQUENTAM & 21892745 & 509044 & 878169 & 1260328 & 1503238 & 1536442 & 1561863 & 1643652 & 1582683 & 1556682 & 1569091 & 1512725 & 1325389 & 1156581 & 923264 \\
\hline \multirow{5}{*}{ 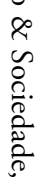 } & NÃO FREQUENTAM & 48919980 & 959256 & 691202 & 382111 & 197217 & 141790 & 124761 & 131695 & 133871 & 159138 & 217964 & 318236 & 439713 & 603239 & 740961 \\
\hline & JA FREQUENTARAM & 39397489 & 75 & 12492 & 22534 & 34738 & 40086 & 46910 & 59090 & 71873 & 99911 & 157747 & 253603 & 369482 & 524074 & 660253 \\
\hline & NUNCA FREQUENTARAM & 9422162 & 953210 & 674183 & 356764 & 161010 & 100565 & 76690 & 71310 & 60746 & 57971 & 58744 & 63659 & 69029 & 77366 & 78210 \\
\hline & SEM DECLARAÇÃO & 100329 & 5971 & 4527 & 2813 & 1469 & 1139 & 1161 & 1295 & 1252 & 1256 & 1473 & 974 & 1202 & 1799 & 2498 \\
\hline & SEM DECLARAÇÃO & 294180 & 127415 & 28527 & 10553 & 3122 & 2370 & 2193 & 3639 & 3443 & 3603 & 3594 & 2288 & 1995 & 2076 & 1848 \\
\hline & & & & & & & & & & & & & & & & \\
\hline & MULHERES & 73486422 & 1542711 & 1544768 & 1605572 & 1645982 & 1627337 & 1649398 & 1723149 & 1672400 & 1685533 & 1769179 & 1824412 & 1764043 & 1758671 & 1651498 \\
\hline \multirow{3}{*}{ 爻 } & FREQUENTAM & 22384540 & 513442 & 876475 & 1250390 & 1476778 & 1510066 & 1548675 & 1619750 & 1563283 & 1546214 & 1563364 & 1521003 & 1350879 & 1197870 & 970561 \\
\hline & NÃO FREQUENTAM & 50810477 & 906491 & 641151 & 345113 & 166204 & 115062 & 98655 & 100035 & 105857 & 135955 & 202526 & 301237 & 411132 & 558762 & 679140 \\
\hline & JA FREQUENTARAM & 41155295 & 69 & 12363 & 20912 & 29719 & 34452 & 39240 & 47819 & 63529 & 97048 & 163706 & 260530 & 368163 & 510769 & 631482 \\
\hline & NUNCA FREQUENTARAM & 9557204 & 900723 & 624379 & 321461 & 134928 & 79344 & 58179 & 50886 & 41041 & 37678 & 37324 & 39611 & 41718 & 46153 & 44966 \\
\hline & SEM DECLARAÇÃO & 97978 & 5699 & 4409 & 2740 & 1557 & 1266 & 1236 & 1330 & 1287 & 1229 & 1496 & 1096 & 1251 & 1840 & 2692 \\
\hline & SEM DECLARAÇÃO & 291405 & 122778 & 27142 & 10069 & 3000 & 2209 & 2068 & 3364 & 3260 & 3364 & 3289 & 2172 & 2032 & 2039 & 1797 \\
\hline & & & & & & & & & & & & & & & & \\
\hline
\end{tabular}

Fonte: IBGE - Contagem da População -1996. CD 
1991, para as crianças de 9 anos de idade. No entanto, os níveis de exclusão permanecem relativamente elevados nos extremos do grupo de 7 a 14 anos: 10,8\% aos 7 anos e 16,9\% aos 14 anos.

Considerando-se toda a população de 5 a 17 anos, em 1996 continuavam não freqüentando escola quase 3,2 milhões de pessoas de 7 a 14 anos, e outros 3,4 milhões de 15 a 17 anos e 2,1 milhões de 5 a 6 anos de idade. No conjunto, em 1996 os três grupos etários continuavam acumulando nada menos do que 8,7 milhões de crianças e adolescentes de 5 a 17 anos fora da escola (Tabela 1). Tudo isto mostra que, apesar dos avanços nas décadas de 1980 e 1990, as estimativas obtidas pelo modelo Profluxo continuam subestimando o problema da não-freqüência ou do não-acesso à escola, especialmente quando se leva em conta também a educação infantil de 5 e 6 anos e a escolarização dos adolescentes de 15 a 17 anos.

\section{A exclusão da escola no Brasil em 1996}

A Contagem 1996 compreende também as crianças de 4 anos de idade. Por isso, as tabelas que seguem contemplam a população dos 4 aos 17 anos. No entanto, para efeito de comparação, a análise se aterá principalmente à população de 5 a 17 anos, como nos censos acima analisados.

Se fossem representadas em formato de colunas, as taxas de nãofreqüência à escola nas diferentes idades, dos 5 até os 17 anos, em 1996 (Tabela 3), produziriam um gráfico em forma de "U". Com efeito, iniciando com $42,4 \%$ aos 5 anos, a taxa de não-freqüência cai progressivamente até atingir o nível mínimo de $6,6 \%$ aos 10 anos, subindo, a partir daí, até atingir $42,8 \%$ entre os adolescentes de 17 anos - praticamente o mesmo nível de não-freqüência verificado entre as crianças de 5 anos. Taxas de não-freqüência à escola inferiores a 10\% (na realidade, entre 6,6 e 8,7\%) só se verificaram nos grupos de 8 a 12 anos. Aos 7 anos a referida taxa ainda é superior a $10 \%(10,8 \%)$ e aos 13 já é novamente superior a $10 \%$ $(11,8 \%)$. Isto, considerando-se a não-freqüência total. Em relação a esse aspecto, é importante repetir que a questão do acesso ou da universalização do acesso deve considerar o conjunto dos excluídos da escola, ou seja, o total da não-freqüência, incluindo tanto os que nunca freqüentaram, como os que já freqüentaram, mas que, por qualquer razão, estão fora da escola. Nesse sentido, apesar de todos os avanços verificados nos 16 anos decorridos desde o Censo de 1980 até a Contagem 1996, resta ainda muita estrada a percorrer até a universalização do acesso à escola. No grupo de 7 a 14 anos as taxas de exclusão da escola iniciam com 10,8\% aos 7 anos, atingem o 
ponto mínimo de 6,6\% aos 10 anos, subindo novamente a partir daí até atingir a taxa de $16,9 \%$ aos 14 anos. Nos grupos de 5 a 6 e 15 a 17 as taxas são sempre superiores a $20 \%$, superando os $40 \%$ nas extremidades (5 e 17 anos).

Para os que declararam não estar freqüentando escola, a Contagem 1996 introduziu a discriminação "já freqüentaram" e "nunca freqüentaram". Como se pode ver na Tabela 2 , na parte relativa ao total (homens + mulheres), o número dos que, em 1996, declararam nunca haver freqüentando escola no Brasil está muito longe de ser desprezível. Com efeito, esse número atingia os seguintes patamares para cada idade: 7 anos - 296 mil; 8 anos - 180 mil; 9 anos - 135 mil; 10 anos - 122 mil; 11 anos 102 mil; 12 anos - 96 mil; 13 anos - 96 mil; 14 anos - 103 mil; 15 anos - 111 mil; 16 anos - 124 mil; 17 anos - 123 mil. O total dos que, em 1996, declararam nunca haver freqüentado escola atinge a cifra de mais de 1,1 milhão da faixa de 7 a 14 anos e de quase 400 mil no grupo de 15 a 17 anos. Ou seja, 1,5 milhão dos 7 aos 17 anos. No grupo de 5 a 6 anos, o número dos que nunca freqüentaram chega a quase 2 milhões. Infelizmente

Tabela 3 - Pessoas de 4 a 17 anos de idade, segundo o sexo e freqüência à escola, por idade. Brasil, 1996.

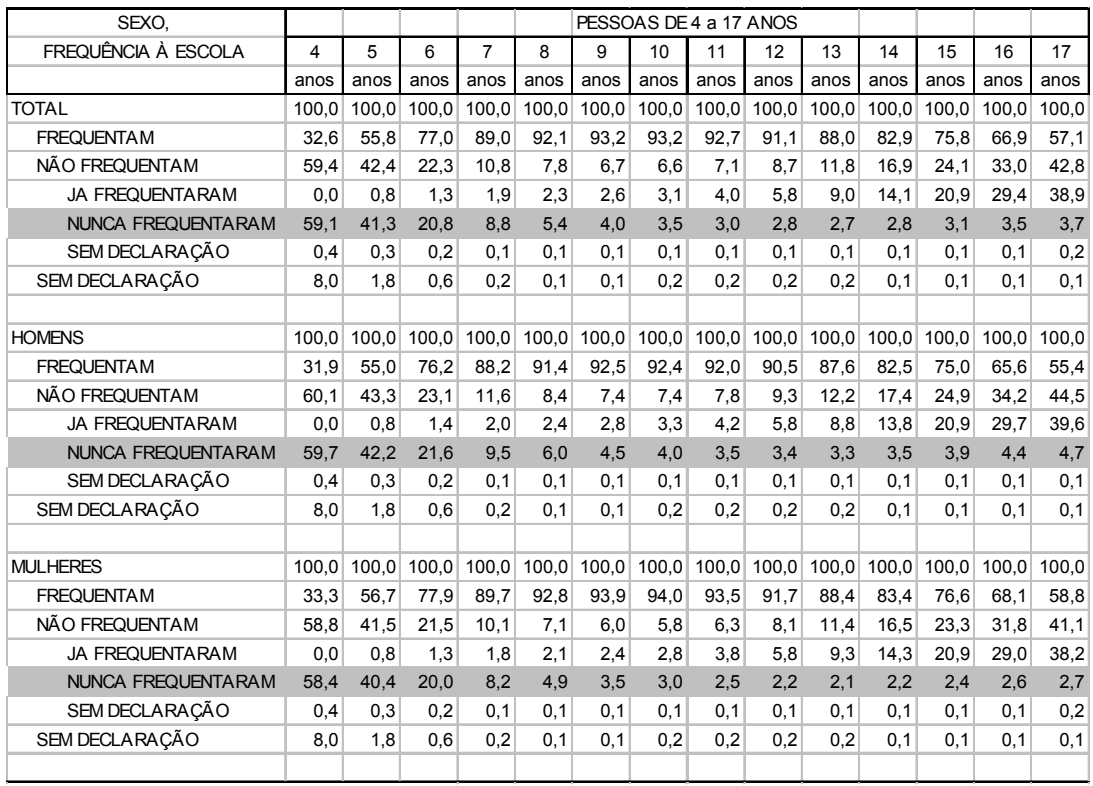

Fonte: IBGE - Contagem da População -1996. CD 


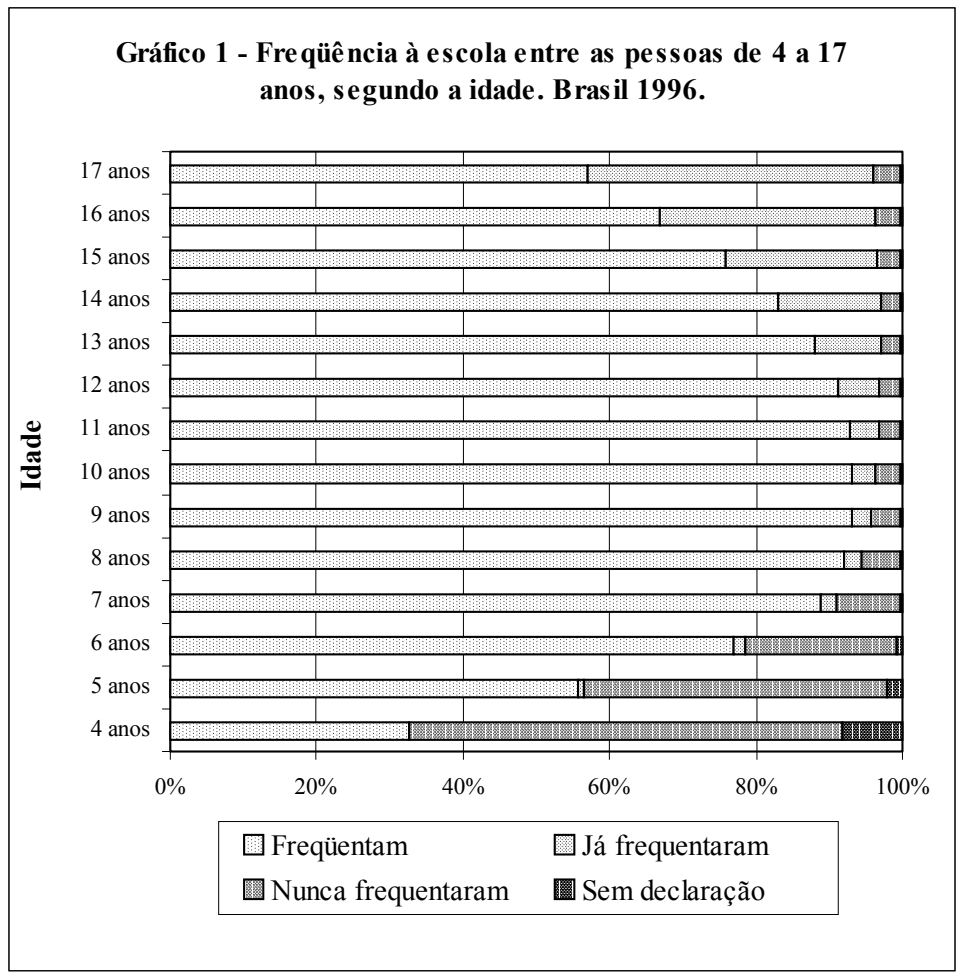

essa informação não foi colhida no Censo de 1991. No entanto, considerando o grande avanço havido no período 1991/1996 em termos de inclusão no sistema escolar, pode-se com segurança supor que o contingente dos que nunca haviam freqüentado escola era bem mais elevado em 1991 do que em 1996.

Concluindo esta parte e antecipando a próxima, concorda-se com Ribeiro, Fletcher e Castro quanto à ênfase que emprestam ao problema da reprovação e repetência, que se definiu como o problema da exclusão na escola, aspecto este analisado em outro lugar (Ferraro, 1999a e 1999b). No entanto, as estatísticas dos censos de 1980 e 1991 e da Contagem 1996 ainda não autorizam concordar com eles em relação à suposta universalização do acesso à escola no Brasil. Oxalá a publicação dos dados do Censo 2000 sobre freqüência à escola confirme, mesmo que com duas décadas de atraso, as estimativas otimistas formuladas primeiramente por Fletcher (1985) para o ano de 1979 e depois por Ribeiro (1990 e 1992) 
para o início dos anos 90. Nas quase duas décadas decorridas entre a avaliação de Fletcher para o ano de 1979 e a Contagem 1996, mesmo reconhecidos todos os avanços no período, a exclusão da escola continuou, sim, representando um problema no Brasil.

O Gráfico 1 permite uma observação importante: à medida que se reduz, a partir das idades mais jovens, a taxa dos que nunca freqüentaram, a qual atinge seus níveis mais baixos (inferiores a 4\%) a partir dos 10 anos, eleva-se rapidamente a taxa dos não freqüentes que já freqüentaram. A soma das duas taxas (nunca freqüentaram + já freqüentaram), que começa decrescendo a partir das idades mais jovens (4 a 5 anos), atinge o nível mínimo entre as crianças de 10 anos, tornando-se crescente a partir daí até os 17 anos. O resultado gráfico da não-frequiência total é um "C" invertido.

\section{A exclusão da escola nas diferentes Unidades da Federação}

O processo de análise desenvolvido nas tabelas 2 e 3 e no gráfico 1, em relação ao Brasil como um todo, foi aplicado também, individualmente, a cada Unidade da Federação. Os resultados estão sintetizados na tabela 4. Esta contém, para cada Unidade da Federação e para cada idade, dos 4 aos 17 anos, os dois indicadores seguintes: 1) a percentagem da não freqüência total (já freqüentaram + nunca freqüentaram) e 2) a percentagem dos que nunca freqüentaram. Com base nos dados da Tabela 4 foram construídos os gráficos 2, 3 e 4, que contemplam respectivamente a idade de 7 anos, 9 anos e 14 anos. Tanto a tabela 4 como os três gráficos permitem o estudo comparativo das diferentes Unidades da Federação em termos dos dois indicadores acima referidos, tendo sempre como parâmetro o Brasil. Os resultados dessa análise são sumariados a seguir.

a) São gritantes as desigualdades regionais, não importa qual a idade que se considere e qual dos dois indicadores se utilize. Por exemplo, para as crianças de 9 anos de idade (Gráfico 3), a taxa de não-freqüência varia de um mínimo 2,1\% em Santa Catarina e Rio Grande do Sul, até um máximo de 18,5\% no Acre e 18,8\% em Alagoas. Já a taxa correspondente a nunca freqüentaram varia de $0,8 \%$ em Santa Catarina e Distrito Federal a $14 \%$ em Alagoas e $14,6 \%$ no Acre, sendo estas últimas cerca de 18 vezes mais elevadas do que a primeira.

b) Os autores que dão por realizada a universalização do acesso à escola no Brasil (Fletcher, Ribeiro, Castro e Klein) tendem 


\section{Tabela 4}

Percentagem de pessoas de 4 a 17 anos, que não freqüentam e nunca freqüentaram, no Brasil e nas diferentes Unidades da Federação

\begin{tabular}{|c|c|c|c|c|c|c|c|c|c|c|c|c|c|c|}
\hline \multirow{2}{*}{$\begin{array}{l}\text { Frequiência à } \\
\text { escolla }\end{array}$} & \multicolumn{14}{|c|}{ Pessoas de 4 a 17 anos } \\
\hline & $\begin{array}{c}4 \\
\text { anos } \\
\end{array}$ & $\begin{array}{c}5 \\
\text { anos } \\
\end{array}$ & $\begin{array}{c}6 \\
\text { anos } \\
\end{array}$ & $\begin{array}{c}7 \\
\text { anos } \\
\end{array}$ & \begin{tabular}{|c|}
8 \\
anos \\
\end{tabular} & $\begin{array}{c}9 \\
\text { anos }\end{array}$ & \begin{tabular}{|c|}
10 \\
anos \\
\end{tabular} & \begin{tabular}{|c|}
11 \\
anos
\end{tabular} & \begin{tabular}{|c|}
12 \\
anos \\
\end{tabular} & $\begin{array}{c}13 \\
\text { anos }\end{array}$ & \begin{tabular}{|c|}
14 \\
anos \\
\end{tabular} & \begin{tabular}{|c|}
15 \\
anos \\
\end{tabular} & \begin{tabular}{|c|}
16 \\
anos \\
\end{tabular} & \begin{tabular}{|c|c|}
17 \\
anos
\end{tabular} \\
\hline \multicolumn{15}{|l|}{ Brasil } \\
\hline Não $F_{1}$ & 59,4 & 42,4 & 22,3 & 10,8 & 7,8 & 6,7 & 6,6 & 7,1 & 8,7 & 11,8 & 16,9 & 24,1 & 33,0 & 42,8 \\
\hline Nunca Freq & 59,1 & 41,3 & 20,8 & 8,8 & 5,4 & 4,0 & 3,5 & 3,0 & 2,8 & 2,7 & 2,8 & 3,1 & 3,5 & 3,7 \\
\hline \multicolumn{15}{|l|}{ Rondônia } \\
\hline Não Frequi & 72,2 & 61,4 & 36,8 & 13,8 & 8,2 & 6,8 & 7,0 & 10,5 & 16,2 & 23,2 & 30,5 & 39,4 & 48,6 & 56,2 \\
\hline Nunca Fr & 71,7 & 60,4 & 35,1 & 11,4 & 5,0 & 3,1 & 2,1 & 1,9 & 1,7 & 1,9 & 1,7 & 2,0 & 2,2 & 2,3 \\
\hline \multicolumn{15}{|l|}{ Acre } \\
\hline NãoF & 71,3 & 58,4 & 40,1 & 25,8 & 21,9 & 18,5 & 17,4 & 17,6 & 17,8 & 20,3 & 24,3 & 31,7 & 39,6 & 47,5 \\
\hline Nunca & 71,0 & 57,6 & 38,6 & 23,5 & 18,7 & 14,6 & 13,1 & 11,7 & 10,5 & 9,9 & 9,3 & 10,4 & 10,9 & 11,3 \\
\hline \multicolumn{15}{|l|}{ Amzzonas } \\
\hline Não Freqi & 62,2 & 51,4 & 35,6 & 22,9 & 18,3 & 15,3 & 14,9 & 13,8 & 14,8 & 17,1 & 20,9 & 27,2 & 34,9 & 43,5 \\
\hline Nunca & 61,7 & 49,9 & 33,1 & 19,0 & 13,7 & 10,2 & 9,2 & 7,4 & 6,8 & 6,3 & 6,2 & 6,4 & 7,2 & 7,0 \\
\hline \multicolumn{15}{|l|}{ Roraima } \\
\hline Não Fre & 41,9 & 36,8 & 24,0 & 13,5 & 8,8 & 7,9 & 7,8 & 8,1 & 9,3 & 11,8 & 15,8 & 22,9 & 31,6 & 41,0 \\
\hline & 41,7 & 35,4 & 22,3 & 11,4 & 6,2 & 5,0 & 4,8 & 4,6 & 4,5 & 4,0 & 4,0 & 4,1 & 5,2 & 5,1 \\
\hline \multicolumn{15}{|l|}{ Pará } \\
\hline Não Fi & 57,9 & 45,1 & 31,2 & 19,5 & 15,0 & 12,4 & 11,6 & 11,3 & 12,3 & 14,9 & 19,9 & 27,4 & 36,1 & 45,2 \\
\hline Nunc & 57,6 & 43,7 & 28,9 & 16,5 & 11,4 & 8,3 & 6,9 & 5,7 & 5,0 & 4,6 & 4,5 & 4,9 & 5,2 & 5,3 \\
\hline \multicolumn{15}{|l|}{ Amapá } \\
\hline $\mathrm{N}$ & 57,7 & 39,2 & 23,0 & 12,8 & 10,0 & 8,5 & 7,8 & 7,8 & 8,6 & 10,8 & 14,7 & 20,5 & 27,2 & 34,7 \\
\hline Nunca & 57,5 & 38,2 & 21,5 & 10,5 & 6,8 & 5,0 & 3,9 & 3,3 & 3,0 & 2,4 & 2,8 & 2,9 & 3,0 & 3,3 \\
\hline \multicolumn{15}{|l|}{ Tocantins } \\
\hline & 5,0 & 57,1 & 31,1 & 16,9 & 11,8 & 9,1 & 8,1 & 7,9 & 8,8 & 11,1 & 15,0 & 21,8 & 30,7 & 38,9 \\
\hline Nunc & 74,7 & 56,1 & 29,4 & 14,4 & 8,6 & 5,5 & 4,3 & 3,4 & 2,8 & 2,7 & 2,5 & 3,0 & 3,4 & 3,6 \\
\hline \multicolumn{15}{|l|}{ Maranhão } \\
\hline & 1,8 & 40,3 & 29,0 & 20,5 & 16,8 & 14,3 & 13,5 & 12,8 & 13,9 & 16,0 & 20,5 & 28,1 & 37,6 & 47,2 \\
\hline & 51,5 & 39,1 & 26,9 & 17,4 & 13,4 & 10,5 & 9,2 & 7,9 & 7,5 & 6,9 & 7,2 & 8,1 & 8,8 & 9,1 \\
\hline \multicolumn{15}{|l|}{ Piauí } \\
\hline & & 42,6 & 29,6 & 19,5 & 15,1 & 12,7 & 11,8 & 11,4 & 12,8 & 15,9 & 21,4 & 29,7 & 39,7 & 49,3 \\
\hline Nun & 55,2 & 41,5 & 28,0 & 17,1 & 12,2 & 9,3 & 8,1 & 6,8 & 6,6 & 6,3 & 6,8 & 7,6 & 8,4 & 9,0 \\
\hline \multicolumn{15}{|l|}{ Ceará } \\
\hline & 45,7 & 30,9 & 19,1 & 13,0 & 10,8 & 9,4 & 9,1 & 9,1 & 10,3 & 13,1 & 18,0 & 24,9 & 34,6 & 44,8 \\
\hline Nunca $\mathrm{F}$ & 45,5 & 29,5 & 17,2 & 10,5 & 7,9 & 6,3 & 5,5 & 4,8 & 4,6 & 4,6 & 4,9 & 5,5 & 6,5 & 7,1 \\
\hline \multicolumn{15}{|l|}{ Rio Grande } \\
\hline & 45,2 & 33,1 & 21,7 & 12,7 & 10,2 & 9,0 & 8,6 & 9,2 & 10,3 & 13,8 & 18,8 & 25,2 & 33,4 & 42,4 \\
\hline Nunc: & 45,0 & 31,6 & 19,6 & 9,9 & 6,9 & 5,2 & 4,5 & 4,2 & 3,8 & 3,9 & 4,2 & 4,6 & 5,4 & 5,6 \\
\hline \multicolumn{15}{|l|}{ Paraíba } \\
\hline & & 38,5 & 24,0 & 16,2 & 13,2 & 11,8 & 11,8 & 12,1 & 13,3 & 17,0 & 22,2 & 29,6 & 38,9 & 47,4 \\
\hline & 58,5 & 37,0 & 21,5 & 13,0 & 9,7 & 7,8 & 7,1 & 6,4 & 6,1 & 6,1 & 6,6 & 7,4 & 8,7 & 9,3 \\
\hline \multicolumn{15}{|l|}{ Pernambuc } \\
\hline & & 35,6 & 22,7 & 14,4 & 11,5 & 10,2 & 10,0 & 10,3 & 12,0 & 15,5 & 20,5 & 27,0 & 34,8 & 43,7 \\
\hline Nunca & 50,5 & 33,9 & 20,4 & 11,2 & 7,9 & 6,2 & 5,4 & 4,7 & 4,4 & 4,4 & 4,6 & 4,9 & 5,5 & 5,9 \\
\hline \multicolumn{15}{|l|}{ Alagoas } \\
\hline & 62,6 & 49,8 & 37,0 & 26,0 & 21,3 & 18,8 & 18,3 & 17,8 & 19,4 & 21,9 & 27,6 & 35,0 & 43,9 & 52,8 \\
\hline Nunca Freqüentaram & 62,3 & 48,3 & 34,5 & 22,6 & 17,0 & 14,0 & 12,9 & 11,4 & 10,8 & 10,5 & 10,9 & 12,0 & 13,0 & 14,0 \\
\hline
\end{tabular}




\section{Tabela 4 - (continuação)}

Percentagem de pessoas de 4 a 17 anos, que não freqüentam e nunca freqüentaram, no Brasil e nas diferentes Unidades da Federação

\begin{tabular}{|c|c|c|c|c|c|c|c|c|c|c|c|c|c|c|}
\hline \multirow{2}{*}{$\begin{array}{c}\text { Freqüência à } \\
\text { escola } \\
\text { (contimuação) }\end{array}$} & \multicolumn{14}{|c|}{ Pessoas de 4 a 17 anos } \\
\hline & $\begin{array}{c}4 \\
\text { anos } \\
\end{array}$ & \begin{tabular}{|c}
5 \\
anos
\end{tabular} & $\begin{array}{c}6 \\
\text { anos }\end{array}$ & \begin{tabular}{|c|}
7 \\
anos \\
\end{tabular} & \begin{tabular}{|c}
8 \\
anos \\
\end{tabular} & \begin{tabular}{|c|}
9 \\
anos \\
\end{tabular} & \begin{tabular}{|c|}
10 \\
anos
\end{tabular} & \begin{tabular}{|c|}
11 \\
anos
\end{tabular} & \begin{tabular}{|c|}
12 \\
anos \\
\end{tabular} & \begin{tabular}{|c}
13 \\
anos \\
\end{tabular} & \begin{tabular}{|c|}
14 \\
anos
\end{tabular} & $\begin{array}{c}15 \\
\text { anos }\end{array}$ & $\begin{array}{c}16 \\
\text { anos }\end{array}$ & $\begin{array}{c}17 \\
\text { anos }\end{array}$ \\
\hline \multicolumn{15}{|l|}{ Sergipe } \\
\hline Não Freqüentam & 42,3 & 30,3 & 20,9 & 14,3 & 11,2 & 9,6 & 9,4 & 9,5 & 10,8 & 13,6 & 18,6 & 25,7 & 34,7 & 43,5 \\
\hline Nunca Freqüentaram & 42,1 & 29,1 & 19,2 & 11,6 & 8,3 & 6,4 & 5,7 & 5,2 & 4,9 & 5,0 & 5,2 & 5,9 & 6,9 & 7,5 \\
\hline \multicolumn{15}{|l|}{ Bahia } \\
\hline Não Freqüentam & 56,5 & 41,3 & 26,7 & 17,0 & 12,9 & 10,8 & 10,4 & 10,1 & 11,3 & 13,5 & 17,9 & 24,8 & 33,5 & 43,3 \\
\hline Nunca Freqüentaram & 56,3 & 39,9 & 24,5 & 14,0 & 9,5 & 7,2 & 6,2 & 5,2 & 5,0 & 4,7 & 4,9 & 5,5 & 6,4 & 6,9 \\
\hline \multicolumn{15}{|l|}{ Minas Gerais } \\
\hline Não Freqüentam & 70,8 & 49,7 & 20,8 & 6,8 & 3,7 & 3,2 & 3,5 & 4,7 & 7,4 & 11,7 & 17,9 & 25,5 & 34,8 & 43,9 \\
\hline Nunca Freqüentaram & 70,4 & 49,1 & 20,0 & 5,7 & 2,3 & 1,6 & 1,4 & 1,2 & 1,3 & 1,3 & 1,5 & 1,7 & 1,9 & 2,2 \\
\hline \multicolumn{15}{|l|}{ Espírito Santo } \\
\hline Não Freqüentam & 59,5 & 42,0 & 21,7 & 7,4 & 4,7 & 4,1 & 4,4 & 6,4 & 9,4 & 13,7 & 19,1 & 26,5 & 34,5 & 44,6 \\
\hline Nunca Freqüentaram & 59,2 & 41,3 & 20,7 & 5,9 & 2,8 & 1,9 & 1,5 & 1,4 & 1,3 & 1,2 & 1,3 & 1,5 & 1,7 & 1,8 \\
\hline \multicolumn{15}{|l|}{ Rio de Janeiro } \\
\hline Não Freqüentam & 38,1 & 24,5 & 12,9 & 6,2 & 4,3 & 3,8 & 3,8 & 4,0 & 5,1 & 7,4 & 11,8 & 18,3 & 27,2 & 38,4 \\
\hline Nunca Freqüentaram & 37,5 & 22,9 & 11,1 & 4,3 & 2,2 & 1,5 & 1,2 & 1,0 & 0,9 & 1,0 & 1,1 & 1,2 & 1,2 & 1,3 \\
\hline \multicolumn{15}{|l|}{ São Paulo } \\
\hline Não Freqüentam & 57,3 & 37,3 & 16,2 & 6,0 & 3,2 & 2,8 & 3,0 & 3,5 & 4,8 & 7,4 & 11,8 & 18,1 & 26,5 & 36,7 \\
\hline Nunca Freqüentaram & 56,7 & 36,3 & 15,1 & 4,6 & 1,6 & 1,0 & 0,9 & 0,8 & 0,7 & 0,8 & 0,8 & 0,9 & 0,9 & 1,0 \\
\hline \multicolumn{15}{|l|}{ Paraná } \\
\hline Não Freqüentam & 75,8 & 56,3 & 24,4 & 6,5 & 3,6 & 3,3 & 3,8 & 5,4 & 8,4 & 13,1 & 19,5 & 27,7 & 36,6 & 46,1 \\
\hline Nunca Freqüentaram & 75,6 & 55,9 & 23,6 & 5,3 & 2,2 & 1,4 & 1,2 & 1,0 & 1,0 & 1,0 & 1,1 & 1,3 & 1,3 & 1,5 \\
\hline \multicolumn{15}{|l|}{ Santa Catarina } \\
\hline Não Freqüentam & 61,3 & 42,9 & 18,2 & 4,1 & 2,2 & 2,1 & 2,4 & 4,1 & 7,0 & 12,1 & 19,3 & 28,4 & 38,8 & 50,2 \\
\hline Nunca Freqüentaram & 60,8 & 42,2 & 17,4 & 3,2 & 1,2 & 0,8 & 0,7 & 0,6 & 0,7 & 0,7 & 0,8 & 0,9 & 1,0 & 0,9 \\
\hline \multicolumn{15}{|l|}{ Rio Grande do Sul } \\
\hline Não Freqüentam & 80,2 & 59,8 & 24,6 & 5,2 & 2,5 & 2,1 & 2,3 & 3,0 & 5,0 & 9,1 & 16,1 & 24,9 & 34,7 & 46,2 \\
\hline Nunca Freqüentaram & 80,0 & 59,3 & 23,9 & 4,5 & 1,6 & 1,0 & 0,9 & 0,8 & 0,7 & 0,8 & 1,0 & 1,0 & 1,0 & 1,1 \\
\hline \multicolumn{15}{|l|}{ Mato Grosso do Sul } \\
\hline Não Freqüentam & 77,0 & 56,1 & 25,9 & 11,1 & 7,4 & 6,3 & 6,3 & 7,1 & 9,3 & 13,2 & 19,1 & 27,1 & 36,4 & 46,0 \\
\hline Nunca Freqüentaram & 76,8 & 55,5 & 24,7 & 9,0 & 4,8 & 3,1 & 2,5 & 2,1 & 1,9 & 1,7 & 1,9 & 2,2 & 2,4 & 2,4 \\
\hline \multicolumn{15}{|l|}{ Mato Grosso } \\
\hline Não Freqüentam & 69,3 & 55,0 & 28,7 & 11,3 & 7,6 & 6,3 & 6,2 & 7,2 & 9,6 & 14,0 & 20,7 & 28,7 & 38,1 & 47,8 \\
\hline Nunca Freqüentaram & 68,5 & 53,7 & 27,0 & 8,9 & 4,7 & 2,9 & 2,2 & 1,8 & 1,7 & 1,7 & 1,8 & 2,1 & 2,2 & 2,3 \\
\hline \multicolumn{15}{|l|}{ Goiás } \\
\hline Não Freqüentam & 68,3 & 45,0 & 18,9 & 7,3 & 4,6 & 4,0 & 3,9 & 4,3 & 5,6 & 8,8 & 14,1 & 22,0 & 31,5 & 42,2 \\
\hline Nunca Freqüentaram & 68,0 & 44,3 & 17,5 & 5,5 & 2,6 & 1,7 & 1,3 & 1,2 & 1,1 & 1,1 & 1,2 & 1,5 & 1,6 & 1,8 \\
\hline \multicolumn{15}{|l|}{ Distrito Federal } \\
\hline Não Freqüentam & 52,8 & 33,8 & 18,4 & 4,9 & 2,6 & 2,3 & 2,0 & 2,3 & 2,7 & 3,8 & 6,6 & 10,9 & 18,5 & 27,3 \\
\hline Nunca Freqüentaram & 52,7 & 32,9 & 17,3 & 3,8 & 1,3 & 0,8 & 0,6 & 0,6 & 0,5 & 0,5 & 0,6 & 0,7 & 0,8 & 0,9 \\
\hline
\end{tabular}

Fonte: IBGE - Contagem da População -1996 
a minimizar o problema da evasão. Contrariando essa posição, a Tabela 3 mostra como, para todas as Unidades da Federação, já entre as crianças de 7 anos de idade, é expressiva a diferença entre não freqüentam e nunca freqüentaram. Para o Brasil como um todo, de cada 100 crianças de 7 anos, 11 (10,8\%) não freqüentavam escola, das quais duas já haviam freqüentado, o que equivale a dizer que eram evadidas. Isto significa que já aos 7 anos a evasão representava algo entre $1 / 5$ e 1/6 do total da não-freqüência. Em alguns estados essa proporção é maior; em outros, menor. Entre cada 100 crianças de nove anos, aproximadamente $7(6,7 \%)$ não freqüentam escola, das quais 3 já freqüentaram $(2,7 \%)$. Em todos os estados com taxas inferiores ao índice nacional, mais de metade da não-freqüência é de crianças que já freqüentaram e abandonaram a escola. Mas é no grupo de adolescentes de 14 anos que se pode avaliar todo peso da evasão sobre o total da não-freqüência (Tabela 4). No Rio Grande do Sul, por exemplo, de cada 100 adolescentes de 14 anos, 16,1\% eram não-freqüentes, dos quais apenas $1 \%$ nunca freqüentara. Os outros $15,1 \%$ haviam freqüentado e posteriormente abandonado a escola.

c) É duplamente equivocada a interpretação de Ribeiro (1992, p. 26-27), segundo a qual o remanescente não-acesso à escola (cerca de 5\%, segundo ele, no início dos anos 90) se distribuiria aproximadamente meio a meio (2 a 3\%) entre excepcionais e nordestinos rurais pobres. Primeiro, porque as taxas elevadas de nunca freqüentaram não se limitam ao Nordeste; ao contrário, atingem também, na mesma intensidade, praticamente toda a Região Norte, como se pode ver na tabela 4 e no gráfico 2 . Segundo, porque, de acordo com a argumentação do autor, fora da Região Nordeste, as taxas de nunca freqüentaram traduziriam principalmente a incidência de casos de excepcionalidade. Mas, se assim fosse, como explicar uma variação tão grande, entre as Unidades não nordestinas da Federação, da suposta taxa de excepcionais, que vai dos $0,8 \%$ a $1 \%$ nos estados de Santa Catarina, Distrito Federal, São Paulo e Rio Grande do Sul, a $1,4 \%$ no Paraná, $1,5 \%$ no Rio de Janeiro, 1,6\% em Minas Gerais, 1,7\% em Goiás, 1,9\% no Espírito Santo, 2,9\% no Mato Grosso e 3,1 no Mato Grosso do Sul, sem falar da Região Norte, onde essa taxa atinge níveis entre 3,1\% em Roraima e $14,6 \%$ no Acre? 


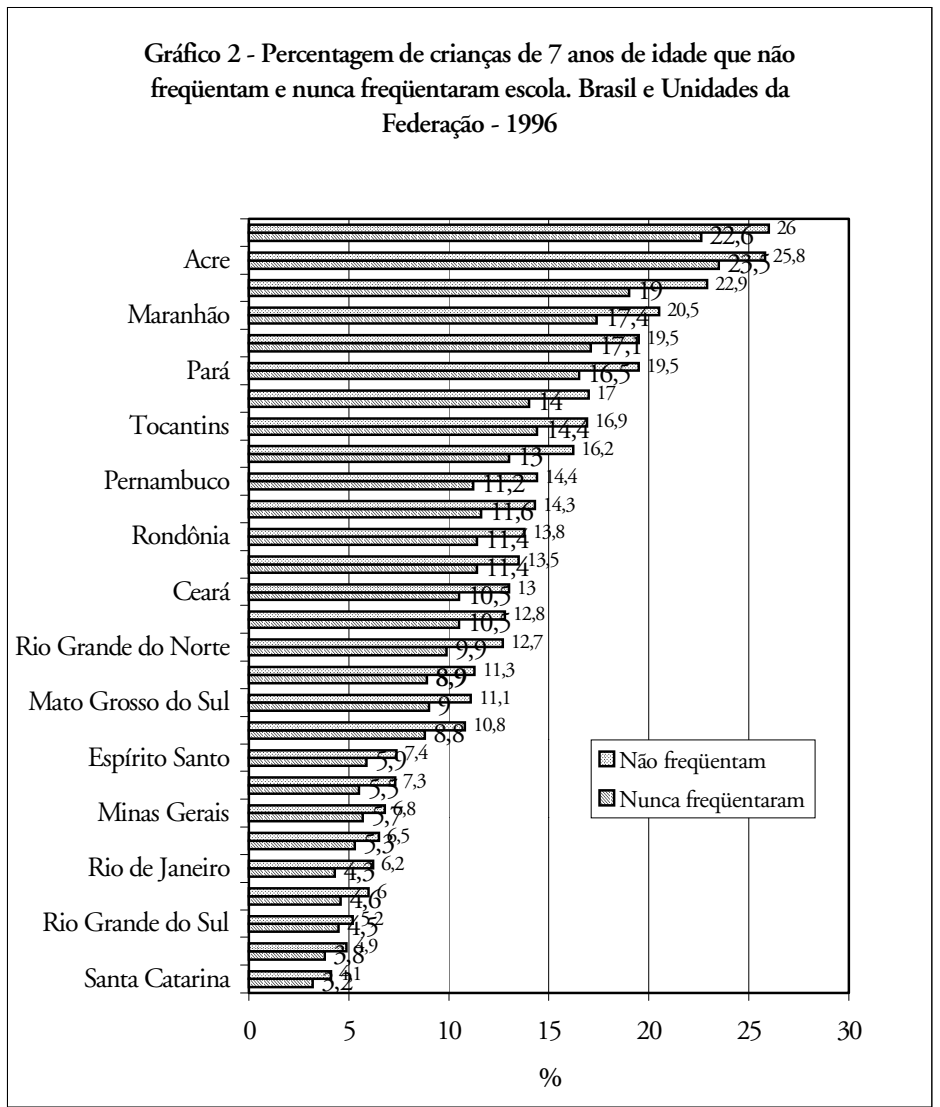

Fonte: Tabela 4

d) Como se pode constatar no gráfico 2, aos 7 anos é praticamente perfeita a correlação positiva entre a taxa de nãofreqüência total e a taxa de nunca freqüentaram: quanto mais elevada uma, tanto mais elevada a outra, e vice-versa, com pequena diferença entre uma e outra. Essa correlação mantém-se também no grupo de 9 anos de idade (gráfico 3), mas já com distância bem maior entre as duas taxas. Já no grupo de 14 anos a correlação positiva entre as duas taxas praticamente desaparece. Por exemplo, a taxas quase idênticas de nunca freqüentaram entre adolescentes de 14 anos, como as apuradas em Rondônia (1,7\%), Mato Grosso $(1,8 \%)$ e Minas Gerais $(1,5 \%)$, correspondem taxas extremamente diferen- 
ciadas de não freqüência total (respectivamente 30,5\%, 20,7\% e $17,9 \%)$. Ou, então, às três taxas mais baixas de nunca freqüentaram (Distrito Federal - 0,6\%, São Paulo - 0,8\% e Santa Catarina - 0,8\%) correspondem taxas muito diferenciadas de não-freqüência total $(6,5 \%, 11,8 \%$ e $19,3 \%$, respectivamente). Isto evidencia que, com o avançar da idade, outros fatores podem intervir no processo de exclusão da escola. Assim, taxas mínimas de nunca freqüentaram podem ser acompanhadas de taxas elevadas de não-freqüência, superiores ao índice nacional, como ocorre entre adolescentes de 14 anos no estado de Santa Catarina (0,8\% e 19,3\%, respectivamente) (gráfico 4).

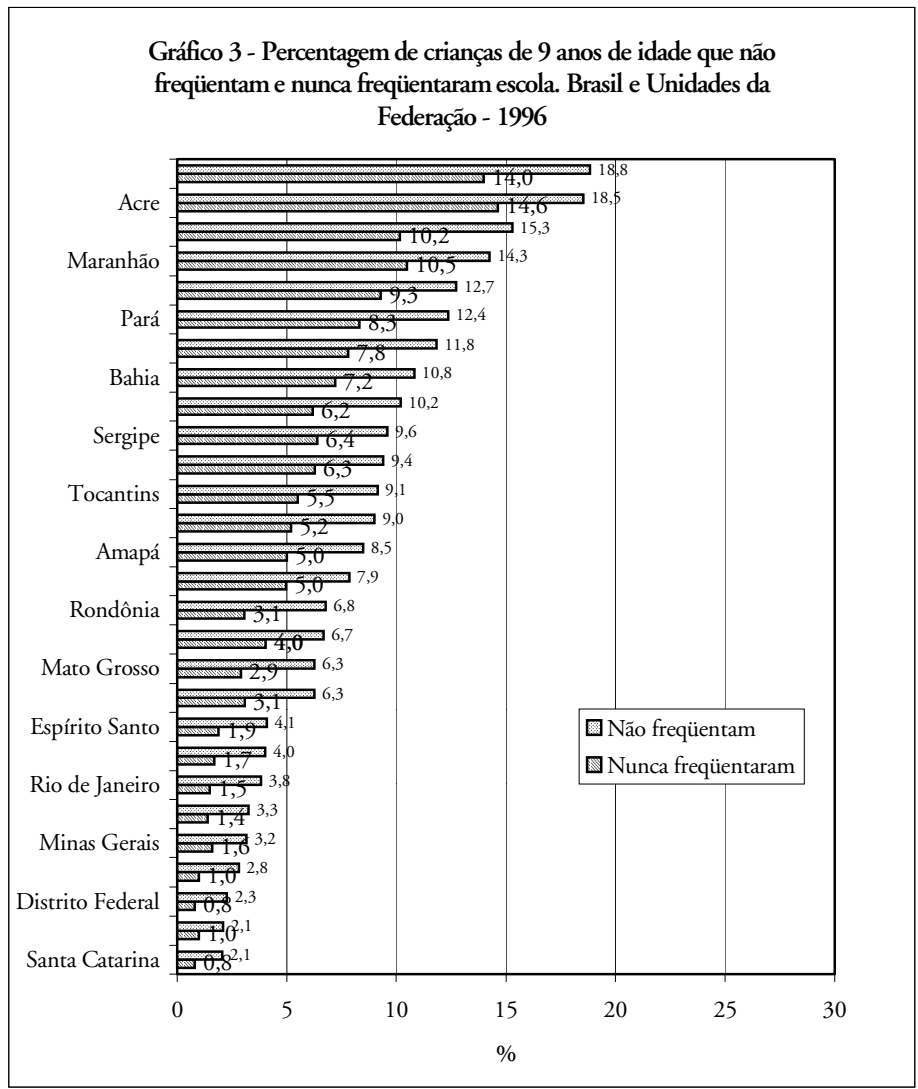

Fonte: Tabela 4 


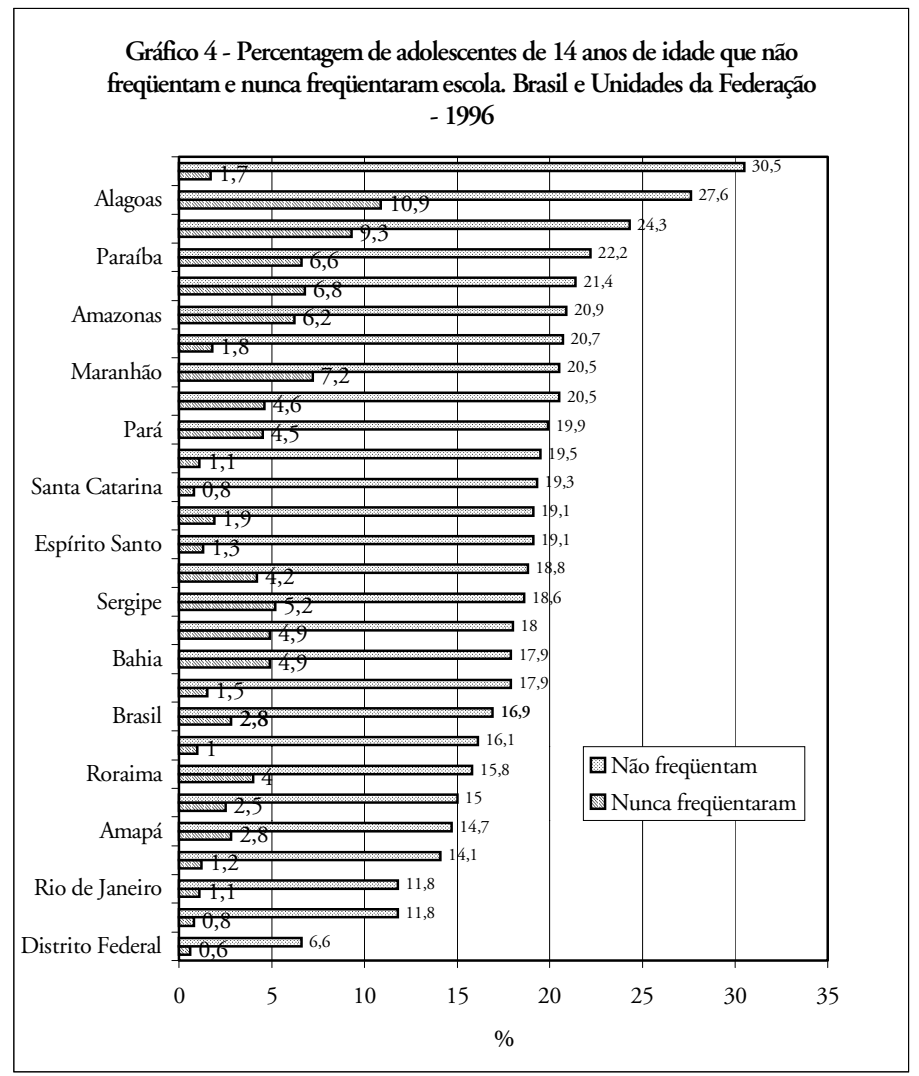

Fonte: Tabela 4

Concluindo esta parte, pode-se dizer que a tese de Ribeiro (1992), que estivemos discutindo acima, incorre em duplo equívoco: primeiro, por reduzir o problema do não-acesso à escola aos que nunca freqüentaram; segundo, por circunscrever o problema do não-acesso (no sentido de "nunca freqüentaram"), à condição de nordestinos rurais pobres ou excepcionais. A análise desenvolvida confirma dois pontos importantes: 1) que o problema de nunca haver tido acesso à escola não pode ser reduzido às condiçôes de nordestino rural pobre ou de excepcional e 2) que o problema do não-acesso ou da exclusão da escola deve ser analisado levando em conta a totalidade da não-freqüência em cada idade, ou seja, o efeito combinado da dupla dimensão da exclusão da escola: a condição de nunca haver freqüentado, mais a condição de "evadido", isto é, de não freqüente que já freqüentou. 


\section{A exclusão da escola segundo o sexo}

Conforme estudo anterior (Ferraro, 1997), eram de se esperam taxas de exclusão da escola menores para crianças e adolescentes do sexo feminino do que do sexo masculino. Tal expectativa se apoiava em diferentes estudos realizados a partir da década de 1950 .

Primeiramente, estudo da UNESCO, do início dos anos 50, fizera duas observaçõos sobre a relação entre sexo e analfabetismo no Brasil A primeira não apresentava nenhuma novidade: referia-se à taxa de analfabetismo notadamente mais elevada entre as mulheres do que entre os homens de 15 anos ou mais, tanto em 1920 como em 1940. Tal fato acompanhava a tendência mundial de taxas de analfabetismo mais elevadas entre as mulheres do que entre os homens. A segunda observação, apoiada em dados do Censo de 1940 desagregados por grupos de idade, identificava uma clara tendência de mudança, porquanto, nesse ano, nos grupos de 10 a 19 anos (grupos mais jovens), a proporção de analfabetos era praticamente a mesma para ambos os sexos: $57,3 \%$ entre os homens e $57,4 \%$ entre as mulheres (UNESCO, 1953, p. 41-42).

Menos de uma década depois desse estudo da Unesco, o Conselho Nacional de Estatística publicou a obra intitulada Contribuições para o Estudo da Demografia no Brasil (CNE, 1961), onde, na parte "G Alfabetização", reúne 9 trabalhos, tão interessantes quanto desconhecidos na área da educação. São sintetizados a seguir os aspectos mais pertinentes e significativos desses estudos (os grifos que seguem são nossos).

a) A situação da instrução primária no Brasil em 1950 era definida como desoladora: "Parece supérfluo qualquer comentário a esses dados desoladores, que falam por si mesmos, revelando o gravíssimo atraso da instrução primária no Brasil. Nos países mais adiantados, quase todas as crianças de 10 anos sabem ler e escrever" (op. cit., p. 434).

b) Para o conjunto da população brasileira, a tendência da alfabetização seguia um padrão bem definido em relação à idade: "A proporção dos que sabem ler e escrever aumenta a partir das idades infantis até as idades moças, declinando depois até a idades senis" (ibid., p. 391). Ou então: “(...) subida (da proporção dos que sabem ler e escrever) nas idades infantis e adolescentes e descida nas idades maduras e senis" (ibid., p. 395).

c) Embora seguindo basicamente esse padrão verificado para o conjunto da população, a marcha da alfabetização em relação à 
idade apresentava notáveis diferenças entre os dois sexos. Segundo o estudo, a histórica "inferioridade feminina" em relação à alfabetização ainda era marcada, manifestando-se a partir do grupo de 20 a 29 anos, sendo mais acentuada nos grupos de idade mais avançada, mas no conjunto tendia a atenuar-se: "A partir do grupo de 20 a 29 anos, a alfabetização feminina mantém-se sempre fortemente inferior à masculina, tendendo a aumentar a inferioridade relativa com o subir da idade" (ibid., p. 389). E ainda: "O aumento da alfabetização foi menor na população masculina de 10 anos e mais (de 48,15\% em 1940 para $52,62 \%$ em 1950) do que na feminina (de 37,99\% para $44,17 \%$ ), atenuando-se assim a inferioridade das mulheres, que, todavia, se mantém ainda bem marcada" (ibid., p. 391).

d) A idade de máxima alfabetização é atingida mais cedo pelas mulheres e somente mais tarde pelos homens, o que é atribuído ao maior aproveitamento da instrução pós-escolar por estes: "A idade de máxima alfabetização é mais elevada no sexo masculino do que no feminino, que parece aproveitar em menor medida a instrução pós-escolar" (ibid., p. 391). E ainda: "Entre as mulheres, a máxima quota de alfabetização é atingida mais cedo, no grupo de 15 a 19 anos" (p. 408-409).

e) Tanto em 1940 como em 1950, nos grupos de 5 a 9 anos e de 10 a 14 anos verificava-se uma "inferioridade dos meninos em relação às meninas" quanto à alfabetização, desvantagem esta que, no Censo de 1950, se estendeu também para a faixa de 15 a 19 anos. Tal inferioridade se deveria, segundo o estudo, ao fato de os meninos serem aproveitados mais do que as meninas para trabalhos extradomésticos (os grifos que seguem continuam sendo nossos):

Nas idades de 5 a 9 e de 10 a 14 anos, em que os meninos são aproveitados mais do que as meninas para trabalhos manuais, ficando amiúde impedidos de freqüentar a escola primária, a quota de alfabetização feminina excede nitidamente a masculina, tanto em 1940 como em 1950. Nos grupos de 15 a 19 anos, em 1950, a quota de alfabetização masculina $(52,65 \%)$ é levemente inferior à feminina $(52,77 \%)$, enquanto que em 1940 a primeira $(46,17 \%)$ excedia a segunda $(44,51 \%)$ (...). Uma característica peculiar da instrução no Brasil, posta em evidência pelos dados da tabela II, consiste na inferioridade das quotas de alfabetização masculinas em relação às femininas. $O$ maior emprego de crianças do sexo masculino em trabalhos extradomésticos, especialmente rurais, parece se o fator principal dessa inferioridade. (Ibid., p. 389 e 434) 
Chega-se assim a um ponto surpreendente e ao mesmo tempo preocupante. $\mathrm{O}$ que parecia indicar uma progressiva superação da histórica discriminação da mulher, em relação ao homem, no que concerne à alfabetização, poderia ser o resultado, não de um avanço relativamente maior das mulheres, mas de uma desaceleração no andar das crianças e adolescentes do sexo masculino rumo a alfabetização, em decorrência de maior solicitação e presença dos meninos do que das meninas no mercado de trabalho.

Foi partindo desses estudos da UNESCO e do CNE que se procedeu, em outro texto (Ferraro, 1997), à análise do comportamento das taxas de analfabetismo de homens e mulheres no estado do Rio Grande do Sul desde o Censo de 1940 até o de 1991. Os resultados em relação às pessoas de 5 a 19 anos em 1991 foram assim sintetizados:

Como se viu acima, no Brasil as taxas de analfabetismo para o conjunto da população de 10 anos ou mais foram e continuam sendo mais elevadas entre as mulheres do que entre os homens. No entanto, desde os censos de 1940 e 1950 isto já não era verdadeiro para os grupos de idade mais jovens (UNESCO, 1953, e CNE, 1961). O censo de 1991 revela que tal mudança se estendeu a outros grupos de idade. Com efeito, em 1991, desde os 5 até aos 19 anos de idade, as mulheres apresentam, tanto no meio urbano como no meio rural, sem exceção, taxas de analfabetismo (segundo o critério censitário) sempre menores do que os homens (...) Na realidade, (...) essa vantagem (taxas mais baixas de analfabetismo) em favor das mulheres se estende até o grupo de 30 a 34 anos (tabela 4). As diferenças a favor das mulheres em relação aos homens estão longe de ser desprezíveis. É o que se pode ver comparando, por exemplo, as taxas de analfabetismo aos 8 anos de idade, que variam de um máximo de $19,3 \%$ entre os meninos rurais, passando por $15,4 \%$ entre as meninas rurais e $15,1 \%$ entre os meninos urbanos, até a taxa mínima de $12,5 \%$ entre as meninas urbanas. A mudança em favor das mulheres nas faixas de idade de 5 a 19 anos é de tal ordem que as taxas de analfabetismo feminino rural caíram quase até o nível do analfabetismo masculino urbano nessas mesmas idades (...). Isto, de um lado, confirma a continuidade, até o Censo de 1991, da mudança já apontada no estudo do CNE relativamente aos censos de 1940 e 1950 e, de outro, atesta a intensificação dessa mesma mudança. (Ferraro, 1997)

Podia-se, portanto, esperar, na presente pesquisa, taxas de exclusão da escola menores para crianças e adolescentes do sexo feminino do que do sexo masculino. A tabela 3, na parte em que desagrega a freqüência e não freqüência por sexo, confirma plenamente essa expectativa. Com efeito, em cada uma das idades consideradas na tabela (4 a 17 anos), as mulheres apresentam sempre taxas mais baixas, seja na categoria não freqüentam, seja na categoria nunca freqüentaram. A diferença sempre 
em favor das mulheres pode ser melhor avaliada se expressa graficamente. É o que mostram o gráfico 4, em relação à categoria não freqüientam, e o gráfico 5 , em relação à categoria nunca freqüentaram.

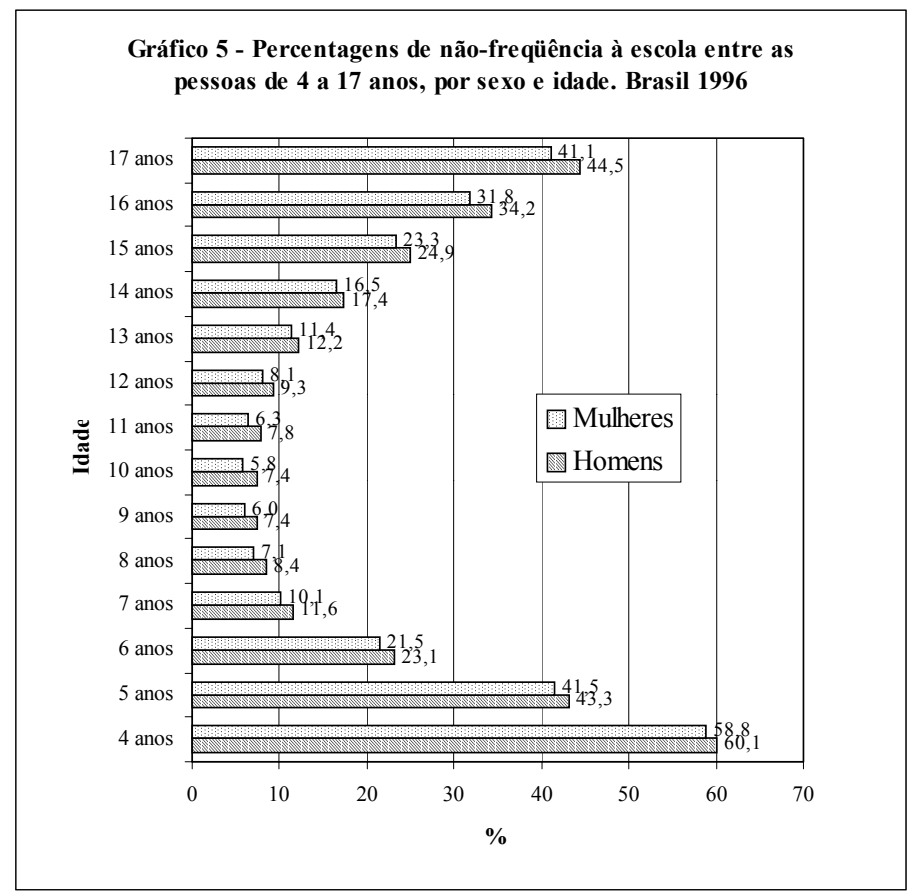

Fonte: Tabela 3

\section{Conclusão}

1. A análise feita com suporte nos dados dos censos demográficos de 1980 e 1991 e da Contagem 1996 evidenciou avanços significativos, no período, em termos de incorporação da população brasileira de crianças e adolescentes no sistema escolar, particularmente nos anos 1991/96. Mas os dados mostraram também que, por maiores que tenham sido esses avanços, o não-acesso à escola, entendido como o conjunto da não-freqüência, ou seja, como o somatório das subcategorias nunca freqüentaram e já freqüentaram (os "evadidos"), continuou, sim, a representar um problema no Brasil nos anos 90. 
2. Mesmo quando considerada apenas a categoria nunca freqüentaram, os dados da Contagem da População 1996 evidenciaram o duplo equívoco da tese de Ribeiro, segundo a qual o problema de nunca ter tido acesso à escola se circunscreveria a uma dessas duas condições: nordestino rural pobre ou excepcional. Em relação à condição nordestinos rurais, a análise desenvolvida mostrou que os estados da Região Norte apresentam taxas aproximadamente tão elevadas de nunca freqüentaram quando os estados do Nordeste. Em relação à condição excepcionais, as variações nas taxas de nunca freqüentaram entre as Unidades não nordestinas da Federação são de tal ordem que não poderiam ser o resultado de variações na taxa de incidência de excepcionais.

3. O problema do não-acesso ou da exclusão da escola deve ser analisado levando em conta a totalidade da não-freqüência em cada idade, ou seja, o efeito combinado da dupla dimensão da exclusão da escola: a condição de nunca haver freqüentado, mais a condição de "evadido", isto é, a condição de não-freqüente que já freqüentou.

4. A justa ênfase no problema da reprovação e repetência (da exclusão na escola) não justifica a desqualificação do problema do não-acesso ainda à escola (da exclusão da escola) em sua dupla dimensão: de nunca freqüentaram + já freqüentaram ("evadiram").

\section{Recebido em novembro de 2001 e aprovado em março de 2002.}

\section{Notas}

1. O projeto de pesquisa Exclusão da escola no Brasil, segundo a Contagem da População 1996, foi desenvolvido no período de março/1999 a fevereiro/2001, no PPG em Desenvolvimento Social da Universidade Católica de Pelotas, com apoio do CNPq. Um dos objetivos da referida pesquisa deu origem a outro artigo, sobre a qualidade das estatísticas originadas dos registros escolares: FERRARO, Alceu R.; VARGAS, Edson L. B.; MACHADO, Nádie C.F. Qualidade das estatísticas originadas dos registros escolares: Um estudo exploratório no Bairro Fragata, na Cidade de Pelotas/RS. Sociedade em Debate, Pelotas/RS, dez. 2001, vol. 7, no 3, p. 47-76.

2. Trata-se do projeto Alfabetização e escolarização de crianças e adolescentes de 5 a 17 anos no Brasil, desenvolvido no período de março/1997 a fevereiro/1999, com apoio do CNPq.

3. Em simpósio realizado na V Conferência Brasileira de Educação, na USP, em 1991, Paulo de Tarso Afonso de André apresentou trabalho intitulado "Escola primária: Trajetórias e determinantes da evasão escolar e da escola pública e da escola privada", em que analisa o 
fenômeno da evasão, dando-lhe destaque, em contraposição aos que minimizam sua importância na educação brasileira. (André, In: Soares et. al., 1992, p. 9-24).

4. Ver Ferraro, Vargas e Machado, na nota 1.

5. Veja-se sobre isto o artigo "Diagnóstico da escolarização no Brasil" (Ferraro, 1999b).

\section{Referências bibliográficas}

ANDRÉ, P.T.A. "Escola primária: Trajetórias e determinantes da evasão escolar e da escolha da escola pública e da escola privada”. In: SoARES, Magda Becker et al. Escola Básica. Campinas: Cedes; São Paulo: AndE; AnPed, 1992. Coletânea CBE. P. 9-24.

CASTRO, C.M. Onde está o desastre? Em aberto, Brasília, out/dez. 1989, vol. 8, no 44, p. 31-33.

FERRARO (FERRARI), Alceu R. Fatores escolares e não escolares do rendimento no ensino de $1^{\circ}$ grau. Estudos Leopoldenses, São Leopoldo (RS), 1975, n o 33, p. 3-64.

Analfabetismo no Brasil: Tendência secular e avanços recentes. Resultados preliminares. Cadernos de Pesquisa, São Paulo: Fundação Carlos Chagas, fev. 1985, no 52, p. 35-49.

. Escola e produção do analfabetismo. Educação \& Realidade, Porto Alegre, jul./dez. 1987, vol. 12, no 2, p. 81-96.

"Atendimento escolar básico: Problemas de diagnóstico". In: SoAres, Magda Becker et al. Escola Básica. Campinas: Cedes; São Paulo: Ande; Anped, 1992. p. 9-24. (Coletânea CBE).

Crianças e adolescentes no Rio Grande do Sul: Trabalho e analfabetismo. Educação \& Realidade, Porto Alegre, jul./dez. 1997, vol. 22, no 2, p. 203-221.

Alfabetização e escolarização de crianças e adolescentes no Brasil: Um diagnóstico. Relatório de Pesquisa para o CNPq, Porto Alegre, abril 1999a. 70p.

. Diagnóstico da escolarização no Brasil. Revista Brasileira de Educação, São Paulo, set./dez. 1999b, no 12, p. 22-47.

.; OLIVEIRA, Avelino R.; RIBEIRO, Marlene. O paradigma da exclusão: Discussão conceptual e pesquisa em educação. CD da 51ª Reunião Anual da SBPC, Porto Alegre, PUC/RS, 1999. Tam- 
bém publicado em Cadernos de Educação, Pelotas, ago./dez. 1999c, vol. 8, no 13, p. 131-145.

FLETCHER, P.R. A repetência no ensino de $1^{\circ}$ grau: Um problema negligenciado da educação brasileira. Uma análise preliminar e sugestão de avaliação adicional. Revista Brasileira de Administração da Educação, Porto Alegre, jan./jun. 1985, vol. 3, no 1, p.10-41.

.; CASTRO, C.M. Os mitos, as estratégias e as prioridades para o ensino de $1^{\circ}$ grau. Educação \& Realidade, Porto Alegre, jan./jun. 1986, vol. 11, no 1, p. 35-42.

.; RIBEIRO, S.C. O ensino de primeiro grau no Brasil de hoje. Em aberto, Brasília, jan./mar. 1987, vol. 6, no 33, p. 1-10.

.; CASTRO, C.M. Mitos, estratégias e prioridades para o ensino de $1^{\circ}$ grau. Estudos em Avaliação Educacional, São Paulo, jul./dez. 1993, no 8, p. 39-56.

IBGE. Censo demográfico 1980. Rio de janeiro: IBGE.

- Censo demográfico 1991. Rio de Janeiro: IBGE.

. Contagem da População 1996. Rio de Janeiro: IBGE, 1997. Vol. I e II e CD I e II.

KLEIN, R.; RIBEIRO, S.C. O censo educacional e o modelo de fluxo. O problema da repetência. Revista Brasileira de Estatística, Rio de Janeiro, jan./dez. 1991, vol. 52, no 197/198, p. 5-45.

RIBEIRO, S.C. A pedagogia da repetência. Tecnologia Educacional, Rio de janeiro, nov./dez. 1990, vol. 19, no 97, p. 13-20.

"A escola brasileira do professor Raimundo". In: SOARES, Magda Becker et al. Escola Básica. Campinas: Cedes; São Paulo: Ande; AnPEd, 1992, p. 25-29 (Coletânea CBE). 